\title{
CORRELAÇÃO ENTRE ÍNDICES DAS ÁRVORES E CLASSES SOCIAIS NA CIDADE DE SERRA TALHADA - PE
}

\author{
Wellington Jorge Cavalcanti Lundgren ${ }^{1}$ Luzia Ferreira da Silva ${ }^{23}$
}

\section{RESUMO}

A cidade de Serra Talhada - PE apresenta problemas visíveis quando se trata de arborização, pois possui poucas árvores, predomínio de Ficus ssp e podas inadequadas. Alguns bairros são mais arborizados do que outros. Nesse trabalho verifica-se a diferença percebida está associada às classes sociais. $\mathrm{O}$ censo das árvores das calçadas da cidade foi realizado, pela UFRPE/Prefeitura Municipal de Serra Talhada. Foram medidas as alturas, as áreas das copas e as árvores foram georreferenciadas e identificadas. A cidade foi dividida em quatro classes sociais, (A, B, C e D). Foram comparados quatro índices das árvores: altura, área de cobertura, adensamento de árvores nas calçadas (AD) e o índice de diversidade de Shannon $(\mathrm{H})$ para cada classe social. A classe social A apresentou para todos os índices os maiores valores, a classe D apresentou os menores valores para todos os índices, as classes $\mathrm{B}, \mathrm{C}$ e D não apresentaram diferença significativa para a área de cobertura. Existe influência das classes sociais nos índices das árvores pesquisados, ou seja, os bairros onde residem as pessoas de classes sociais mais elevadas têm melhores índices das árvores do que os bairros das classes mais baixas.

Palavras-chave: cobertura vegetal; poder aquisitivo; temperatura do ar; semiárido e arborização.

\section{CORRELATION OF URBAN AFFORESTATION AND SOCIAL CLASSES IN SERRA TALHADA CITY - PE \\ Wellington Jorge Cavalcanti Lundgren ${ }^{1}$ Luzia Ferreira da Silva ${ }^{2}$}

\begin{abstract}
ABSTRAT
Serra Talhada city in Pernambuco state, Brazil, is visibly ill wooded, Ficus $s p$ predominance, few trees, and inadequate pruning are observed. Some neighborhoods are more wooded than others. This study investigated whether there are differences between social classes for the parameters studied afforestation. The census of trees from the sidewalks of the city was conducted by UFRPE and City government of Sierra Talhada. We measured the heights and areas of canopy trees were identified and georeferenced. The city was divided into four classes A, B, C and D. We compared four urban forestry parameters: height, area of coverage, trees crowding the sidewalks (AD) and Shannon diversity index (H) for each class. Social class A presented for all parameters the highest values, class D had the lowest values for all parameters, classes $\mathrm{B}, \mathrm{C}$ and $\mathrm{D}$ showed no significant difference in the coverage area. There is the influence of social classes on urban forestry parameters surveyed, the neighborhoods with higher social classes have better environmental quality.
\end{abstract}

Keywords: forest cover; purchasing power; air temperature; semiarid and urban trees.

\footnotetext{
${ }^{1}$ Dr. Engenharia Florestal, UFRPE - Universidade Federal Rural de Pernambuco, Fazenda Saco s/n Serra Talhada - PE, wellingtonlundgren@yahoo.com.br

${ }^{2}$ Dra. Fitotecnia, UFRPE - Universidade Federal Rural de Pernambuco, Fazenda Saco s/n Serra Talhada - PE, luzia.ferreira68@hotmail.com

${ }^{3}$ recebido em 08.04.2013 e aceito para publicação em 15.12.2013
} 
A partir da década de 60 , o crescimento urbano teve uma aceleração expressiva em todo o mundo, segundo Modelski (2011) no ano de 1800 havia apenas 3 cidades com mais de um milhão de habitantes, em 1900 haviam 16, em 1950 o total era de 74 e em 2011 são 442 cidades. Obviamente, um crescimento exponencial como o apresentado, traz consequências danosas no que concerne a organização dessas cidades para problemas ambientais: poluição sonora, do ar, visual, impermeabilidade do solo, aquecimento do ar, etc.

É consenso que a arborização urbana melhora sob vários aspectos o bem estar das pessoas que vivem em cidades. Os benefícios observados pela arborização adequada nos centros urbanos incluem a diminuição da temperatura ambiente, alimentação e moradia para pequenos animais silvestres, controle da poluição sonora e do ar, área de sombreamento e sensação de bem estar. (VIDAL e GONÇALVES, 1999; SILVA, 2000; WESTPHAL, 2000; LEAL et al. 2008).

Como na maior parte do planeta, as cidades brasileiras também cresceram. Segundo Silva e Werle (2007) a maioria cresceu de forma desordenada, porém com a característica de possuir uma distribuição geográfica das classes sociais bem determinada. As pessoas de classes sociais semelhantes procuram morar próximas umas as outras, criando assim bairros compostos por classes sociais diferenciadas.

No Brasil, segundo Vilaça (2001), a separação dos bairros por classes sociais não é completamente homogênea, havendo interseções entre essas divisões. Vários fatores contribuem para identificar o local de moradia ou o agrupamento de uma classe social dentro da cidade, o valor do solo, os serviços públicos, a arquitetura das casas, e o tamanho da área de cada residência, são algumas das características comumente utilizadas.

O IBGE (2010a) utilizou como critérios para identificação das classes sociais o rendimento financeiro por domicílio, o tipo de construção e bens existentes nas residências. Bezerra e Lima (2011) separaram os bairros do município de Paus dos Ferros - RN, por classes sociais seguindo as dimensões das residências, a aparência das casas e a qualidade dos serviços públicos: ruas calçadas, água encanada, iluminação de vias públicas e proximidade de mercados.

Na cidade de Serra Talhada - PE, como em muitas cidades brasileiras, a arborização das calçadas é a critério dos moradores e o poder local não interfere em nenhum dos aspectos que caracterizam a adequada arborização urbana. Não existe orientação sobre que árvore plantar, observando os critérios de porte, copa e raízes que a árvore possui, como conduzir a árvore até seu desenvolvimento final nem local de plantio. A falta de orientação provoca diversos problemas, tais como, árvores inadequadas para as calçadas, pouca variabilidade de espécies, podas constantes e inadequadas. Dantas e Souza (2004) enumeraram as perdas de espécies arbóreas e a qualidade ambiental para a cidade de Campina Grande - PB, decorrentes da ausência de política ambiental pelo poder público.

O objetivo desta pesquisa foi verificar se os índices das árvores estudados são diferentes entre os bairros onde vivem as pessoas das classes sociais A, B, C e D. Alguns trabalhos abordam a relação entre as classes sociais e as 
características das árvores urbanas, (LUCHIARI, 2001; BEZERRA e LIMA, 2011). Esse conhecimento facilitará na escolha do local dentro da cidade em que poderão ampliar as campanhas de conscientização sobre a importância das árvores ou fornecer para a prefeitura a informação do local em que deve ser despendido maior esforço nas ações de paisagismo.

\section{MATERIAL E MÉTODOS}

A cidade de Serra Talhada é localizada na latitude 0759'31" Sul e longitude 38 17'54" Oeste, na Mesorregião do Sertão pernambucano na Microrregião do Pajeú, a uma altitude de 429 metros (M.M.E, 2005). Ela possui população estimada em torno de 80.000 habitantes (IBGE, 2010b).

No período de junho de 2011 a setembro de 2012 foi realizado o censo das árvores localizadas nas calçadas, por duas equipes de três estagiários da Universidade Federal Rural de Pernambuco (UFRPE), lotados na Unidade Acadêmica de Serra Talhada (UAST) com apoio financeiro da Prefeitura Municipal de Serra Talhada (PMST). Eles percorreram as ruas da cidade e anotaram em tabela, os seguintes dados: o nome da rua e do bairro, o número da árvore (para controle interno da pesquisa cada árvore recebeu uma numeração), o número do prédio, a localização geográfica pelo GPS, a altura estimada da árvore, o diâmetro da copa, o espaçamento das árvores da calçada e o nome comum das espécies.

Segundo Silva et al. (2012) a estimativa da altura de árvores em florestas naturais não é um problema resolvido, eles compararam três métodos de estimativas: visual sem treinamento, visual com treinamento e o hipsômetro Vertex e chegaram a conclusão de que a maior precisão ocorreu com método visual com treinamento seguido pelo Vertex e por último o visual sem treinamento. Nesse trabalho a estimativa da altura não tem fins comerciais, não é necessário que a estimativa seja extremamente precisa. Foi utilizado o método visual da sobreposição de intervalos, um estagiário de altura conhecida postava-se próximo à árvore, um segundo estagiário postava-se a uma distância da árvore em que pudesse visualizar entre os dedos polegar e indicador com o braço estendido o primeiro estagiário, de forma que a altura desse primeiro estagiário ficasse completamente dentro do espaço entre os dois dedos. Depois o segundo estagiário sobrepunha a distância entre os dedos na imagem da árvore, contando quantos desses intervalos cabiam até cobrir toda a altura da árvore, depois multiplicava essa quantidade pela altura conhecida do primeiro estagiário (Figura 1). 
Figura 1. Esquema da estimativa de altura de árvore em pé. A pessoa 1 visualiza por entre os dedos polegar e indicador com o braço estendido a pessoa 2, de forma que a visão do corpo da pessoa 2 fique inteiramente entre os dedos da pessoa 1. Então a pessoa 1 sobrepõe a imagem acompanhado a altura da árvore e contando o número de vezes que a abertura dos dedos cobre toda a árvore.

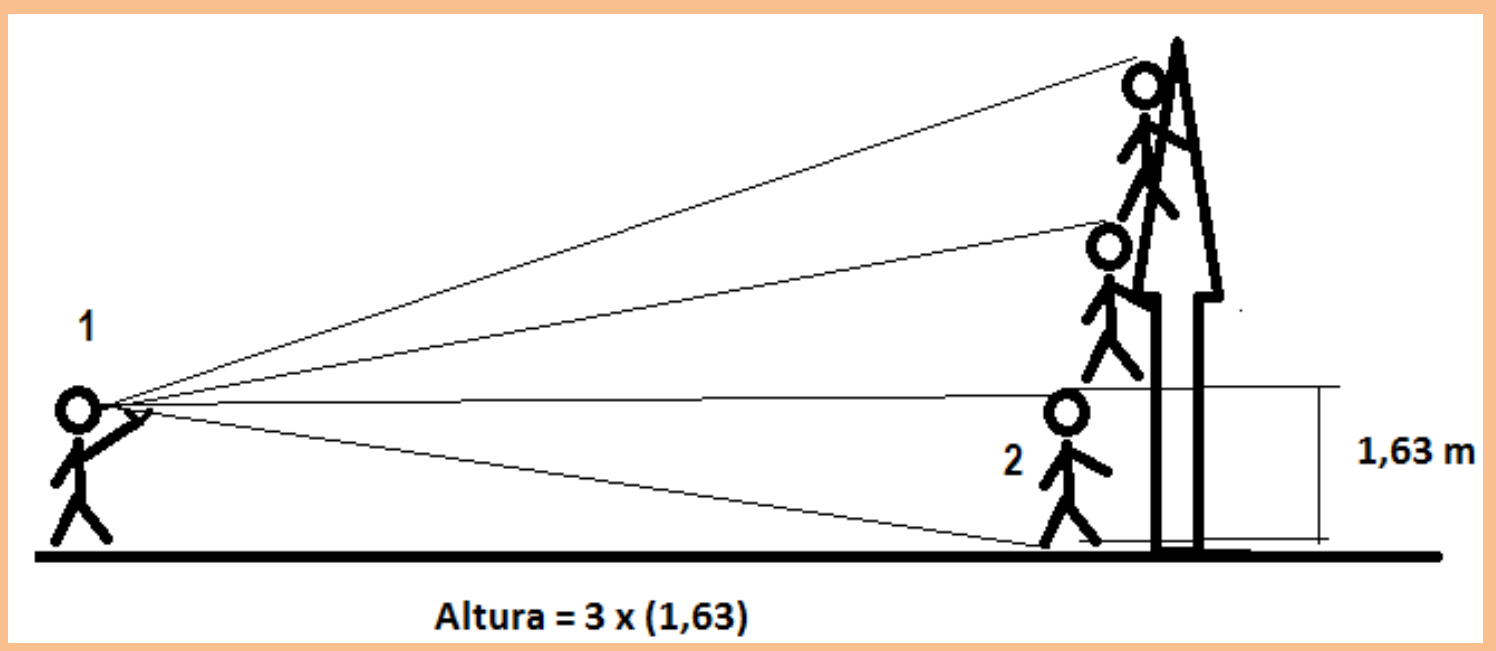

Os dados do GPS foram transferidos para o software Tracmaker e repassados para o software Excel, no qual foram inseridas todas as informações da planilha de coleta e, posteriormente, exportados para o software ArcGis. O software ArcGis possuía o mapa georreferenciado da área urbana de Serra Talhada - PE e com o qual foi possível elaborar o mapa da arborização da cidade, em que a área das copas foi colocada na mesma escala do mapa.

Os bairros da cidade foram demarcados em foto aérea disponível no Google Earth seguindo as demarcações dos bairros definidas por leis municipais de 1989 até o ano de 1995, catalogadas por Lima Filho (2000), portanto, há mais de 15 anos não existe atualização nessas demarcações.
A área de cada bairro e o comprimento das calçadas foram calculados no software ArcGis. Foram quantificadas com o auxílio do software Excel, o número de árvores, as espécies, a área das copas das árvores e a altura das árvores e construídos os histogramas.

Os bairros foram classificados em quatro classes sociais, identificados pelas áreas dos terrenos das residências e pela infraestrutura municipal. $\mathrm{Na}$ classificação dos bairros pela área das residências. Para cada bairro foram sorteados aleatoriamente três quarteirões. A área dos três quarteirões foram medidas e o número de terrenos com ou sem construções foram contados, a média da área/terreno foi calculada. 
Figura 2. Foto aérea de um quarteirão do bairro AABB, mostrando a divisão de 12 terrenos (demarcados em azul) separados visualmente.

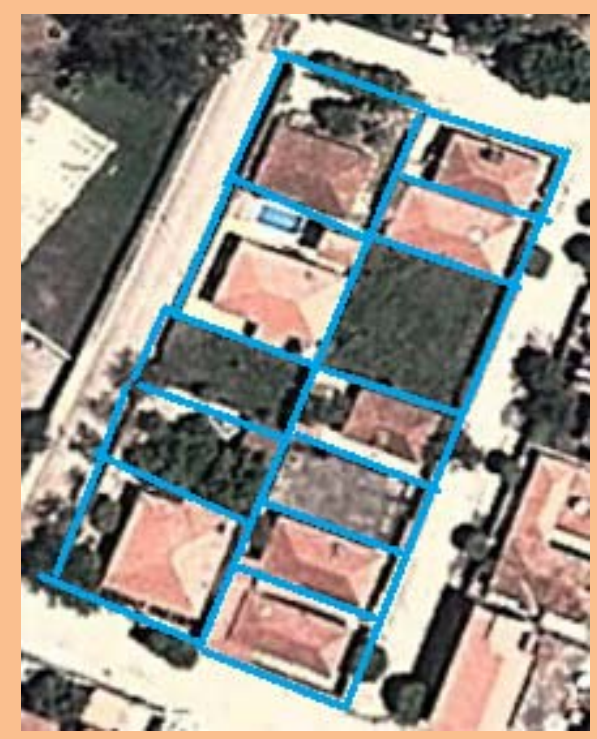

Fonte: Google Earth.

Da classe A fizeram parte os bairros que possuíam a maioria das casas amplas com a maior média de área por casa, com muros altos, arquitetura estilizada, não conjugadas, a maioria das ruas calçadas e os serviços de água e esgoto presentes.

Nos bairros onde reside a classe B, as casas são grandes, a média de área por terrenos é inferior apenas a classe A, não possuem muros altos, são conjugadas e os serviços de água e esgoto funcionam adequadamente a maioria das ruas são calçadas.

Nos bairros onde reside a classe $C$, as casas são menores, a média de área de terrenos por casa é inferior as da classe B, são conjugadas, muitas ruas não são calçadas e todas as casas recebem serviço de água e esgoto.

Nos bairros onde reside a classe D, as casas são pequenas com as menores áreas de terrenos por casa, são conjugadas, a estrutura residencial é básica (sala, quartos, cozinha e banheiro), poucas ruas calçadas e algumas casas não recebem o serviço de esgoto apesar de terem água encanada.

Os critérios adotados por Bezerra e Lima (2011) para a cidade de Paus dos Ferros - RN foram aplicados na divisão das classes sociais por bairros para a cidade de Serra Talhada - PE foi acrescentado na pesquisa aqui apresentada a área média do terreno por casa.

Os critérios de comparação dos índices das árvores entre os bairros foram: a altura e a área de cobertura das árvores, o índice de adensamento $(\mathrm{AD})$ que fornece o número de árvores por quilometro de calçada, esse índice foi utilizado por Rossatto et al. (2008) na cidade de Assis - SP eles encontraram o valor de aproximadamente 38 árvores por quilometro de calçada. 
Para a diversidade de espécies foi utilizado o índice de Shannon para cada classe social. O índice da Shannon foi analisado por Melo (2008) que concluiu que o índice serve apenas como comparativo entre a diversidade e a riqueza de espécies entre duas populações, não tendo nenhum significado pratico quando apresentado sozinho.

Para a altura e a área de cobertura foram construídos os histogramas, calculadas as estatísticas básicas: média, moda, mediana, variância, desvio padrão, máximo e mínimo. Foi efetuada a análise de variância e utilizado o teste de Tukey.

Para a diversidade de espécies foi construída uma tabela contendo o nome comum com o respectivo nome científico e com o número de indivíduos de cada espécie nas classes sociais.

\section{RESULTADOS E DISCUSSÃO}

Usando as imagens aéreas foi possível dividir e demarcar as classes sociais pelo critério área dos terrenos (Tabela 1).

Tabela 1. Classificação das classes sociais por média das áreas de terrenos.

\begin{tabular}{lc}
\hline Área do terreno & Classe social \\
\hline Área $\geq 200 \mathrm{~m}^{2}$ & A \\
$150 \mathrm{~m}^{2} \leq$ Área $<200 \mathrm{~m}^{2}$ & B \\
$100 \mathrm{~m}^{2} \leq$ Área $<150 \mathrm{~m}^{2}$ & $\mathrm{C}$ \\
$<100 \mathrm{~m}^{2}$ & $\mathrm{D}$ \\
\hline
\end{tabular}

A classe social A reside no bairro AABB (Figura 2) e onde são encontradas as maiores casas, com as mansões existente na cidade, é um bairro cujo crescimento mais acentuado começou no ano de 2008 e ainda está em expansão.

A classe B é composta por três bairros, Nossa Senhora da Penha, São Cristovão e IPSEP. Nossa Senhora da Penha, é o bairro que comumente seria chamado de centro. É o primeiro bairro de Serra Talhada - PE, a cidade se originou nele, possui a maior parte do comércio, a igreja matriz, a prefeitura, a câmara de vereadores e diversos órgãos públicos. O bairro de São Cristovão é uma extensão do Nossa Senhora da Penha, não se consegue visualmente perceber que a paisagem urbana tenha mudado circulando entre os dois, a não ser o fato de que no bairro de São Cristovão a quantidade de comércio é menor. $\mathrm{O}$ terceiro bairro que compõe a classe B é o Nossa Senhora da Conceição também conhecido como bairro do IPSEP, basicamente residencial. 
Os bairros que compõem a classe $\mathrm{C}$ são os bairros do Bom Jesus, São Sebastião, CAGEPE e Tancredo Neves todos esses bairros são relativamente novos e são basicamente residenciais, os comércios encontrados neles são de pequeno e médio porte (mercadinhos, salões de beleza e pequenos bares).

Foram classificados como classe D dois bairros da cidade, Cachoeira e o Mutirão. Esses bairros abrigam a população mais carente da cidade, muitos de seus moradores são imigrantes das zonas rurais, o poder público municipal não tem beneficiado esses bairros com estruturas urbanas adequadas.

A construção de mapas de cobertura vegetal e de classes sociais da cidade de Campinas - SP foi realizada por Luchiari (2001) usando imagens fornecidas por satélite, o pesquisador informa que existe correlação entre os índices arbóreos e as classes sociais, porém em sua pesquisa usou apenas dados da cobertura vegetal, não levando em conta outros índices das árvores.

Figura 3. Foto aérea de Serra Talhada - PE com as divisões dos bairros e as classes sociais que neles residem.

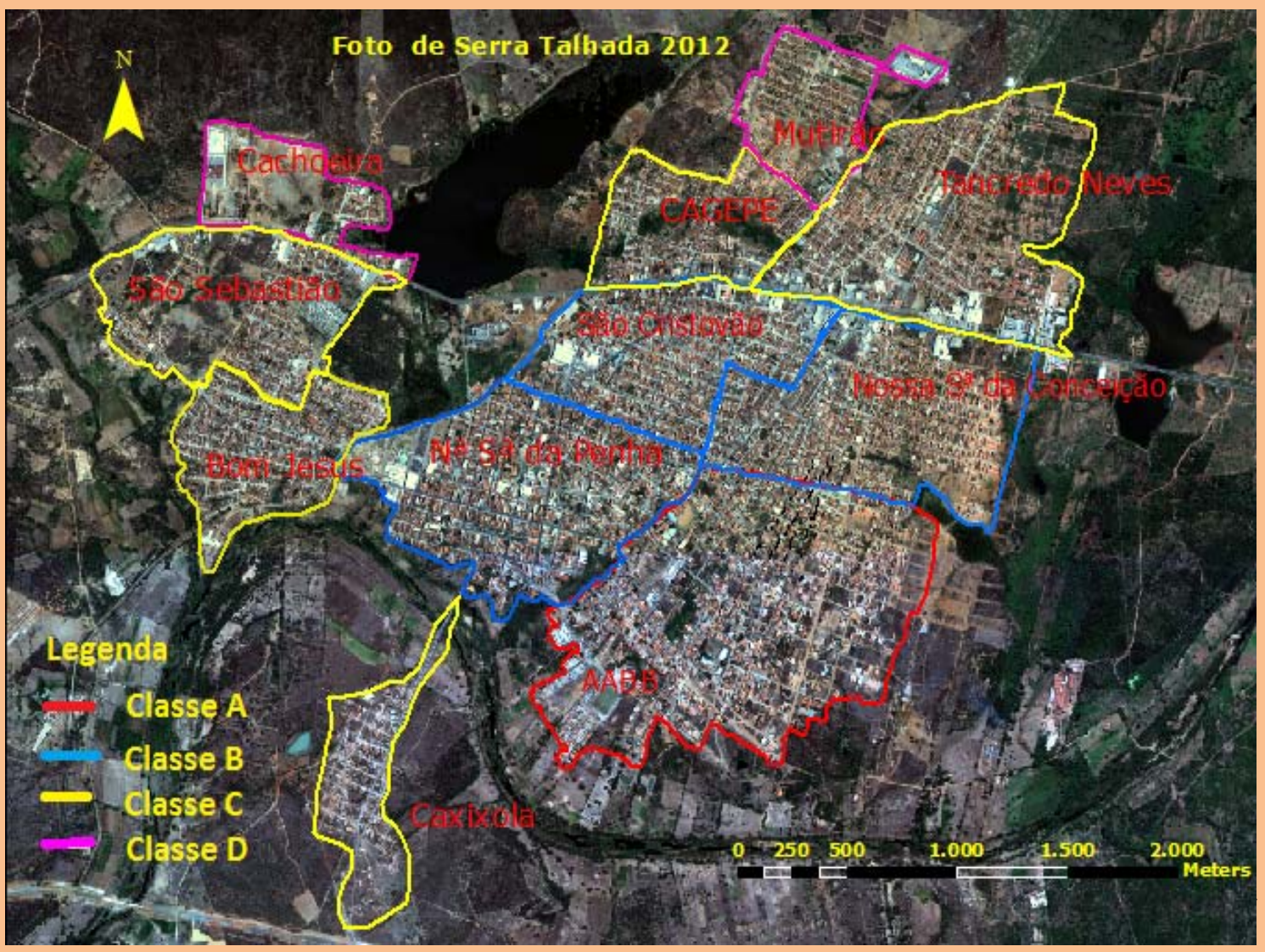

a) Quantidade de árvores por classes sociais

O bairro da $\mathrm{AABB}$ que é o único representando a classe A, teve um total de 1940 árvores plantadas em suas calçadas, o índice de adensamento forneceu para a classe social A o valor de 41,46 árvores por quilômetro de calçada. Meneghetti (2003) usou o número de

CORRELAÇÃO ENTRE ÍNDICES DAS ÁRVORES E... 
árvores por quilômetros de calçadas para a cidade de Santos - SP, porém para chegar a uma estimativa foram utilizadas amostras de ruas e $\mathrm{O}$ bairro que teve maior número de árvores foi o de Nossa Senhora da Penha com 2934 indivíduos, dentre os bairros que compõem a classe B ele é o menor, porém é o que apresentou maior número de árvores entre os três bairros. Somando todas as árvores dos bairros que compõem a classe $\mathrm{B}$, temos o total de 3771 árvores sendo, portanto, essa a classe social que possui o maior número de árvores.

Os bairros da classe $\mathrm{C}$ possuem juntos o total de 2372 árvores, vale ressaltar que o bairro

Tancredo Neves e Caxixola (ambos pertencentes a classe C) são bairros novos, encontrou 39 árvores por quilômetro, valor abaixo do conseguido para o bairro da AABB em Serra Talhada - PE (Tabela 2).

várias ruas ainda não possuem calçamento e muito menos calçadas já definidas, o que não favorece o plantio de árvores em frente as casas. Os bairros Cachoeira e Mutirão possuem juntos 191 árvores, são os bairros com menor área, portanto, o resultado do número de árvores era esperado.

$\mathrm{Na}$ Tabela 2 é possível verificar o resultado da comparação entre as classes sociais para o índice de adensamento.

Tabela 2. Divisão das classes sociais. Comprimento das calçadas em metro. Número de árvores. $\mathrm{AD}=$ Índice de adensamento = Número de árvores/quilômetros de calçadas.

\begin{tabular}{cccc}
\hline Classe Social & Calçadas $(\mathrm{km})$ & $\mathrm{N}^{\circ}$ de árvores & AD \\
\hline A & 46,80 & 1940 & 41,46 \\
B & 95,24 & 3771 & 38,59 \\
C & 57,42 & 2372 & 41,32 \\
D & 7,08 & 191 & 26,99 \\
\hline
\end{tabular}

A pesquisa de Rossato et al. (2008) contabilizou 1915 árvores urbanas em uma amostra na cidade de Assis - SP, eles contabilizaram 37,85 árvores por quilometro de calçada, valor abaixo do que foi encontrado em Serra Talhada - PE. Os autores não encontraram para os índices de arborização correlação com as classes sociais da cidade de Assis.

A classe A representada pelo bairro da AABB possui o maior adensamento de árvores nas calçadas, vale lembrar que esse bairro ainda possui vastas áreas ainda não povoadas, é um bairro novo que está em expansão.

A classe B apresentou um adensamento menor que a classe $\mathrm{C}$, resultado não esperado, pois entre os bairros da classe B está o bairro que originou a cidade que possui sozinho 2934 árvores. Talvez o resultado se deva pela concentração do comércio em parte do bairro de Nossa Senhora da Penha, nas ruas comerciais não existem árvores em suas calçadas, é possível encontrar ruas inteiras sem uma única árvore em suas calçadas.

A classe $C$ é a classe social que ocupa a maior área da cidade e tem um adensamento maior que a classe B e menor do que o da classe A. Todos os bairros da classe $\mathrm{C}$ estão em expansão e todos (ver Figura 2) possuem varias ruas sem calçadas definidas, a densidade de árvores nas calçadas deverá aumentar quando essas ruas estiverem todas prontas. 
A classe $\mathrm{D}$ no que se refere a árvores nas calçadas pode ser considerada como uma região árida, na época da pesquisa o bairro do Mutirão não possuía ruas pavimentadas, nenhuma rua possuía calçada definida, o que não favorece o plantio de árvores. O adensamento de 27 árvores/quilometro de calçada fornece uma clara dimensão do problema urbano no que se refere à

\section{b) Altura das árvores por classes sociais}

Andando-se pelas ruas da cidade a primeira impressão é de que as árvores são todas quase da mesma altura, existe pouca variação entre as arborização em que esses dois bairros estão, principalmente quando associamos a área de cobertura média por árvore que é de $12,90 \mathrm{~m}^{2}$. Cada árvore desse bairro tem uma copa com diâmetro médio de $4.11 \mathrm{~m}$, se alguém andar 1 quilometro passará por baixo de 27 árvores, terá cobertura contra o sol em apenas 110 metros.

Figura 4. Histogramas das alturas das árvores para as classes sociais de Serra Talhada - PE.

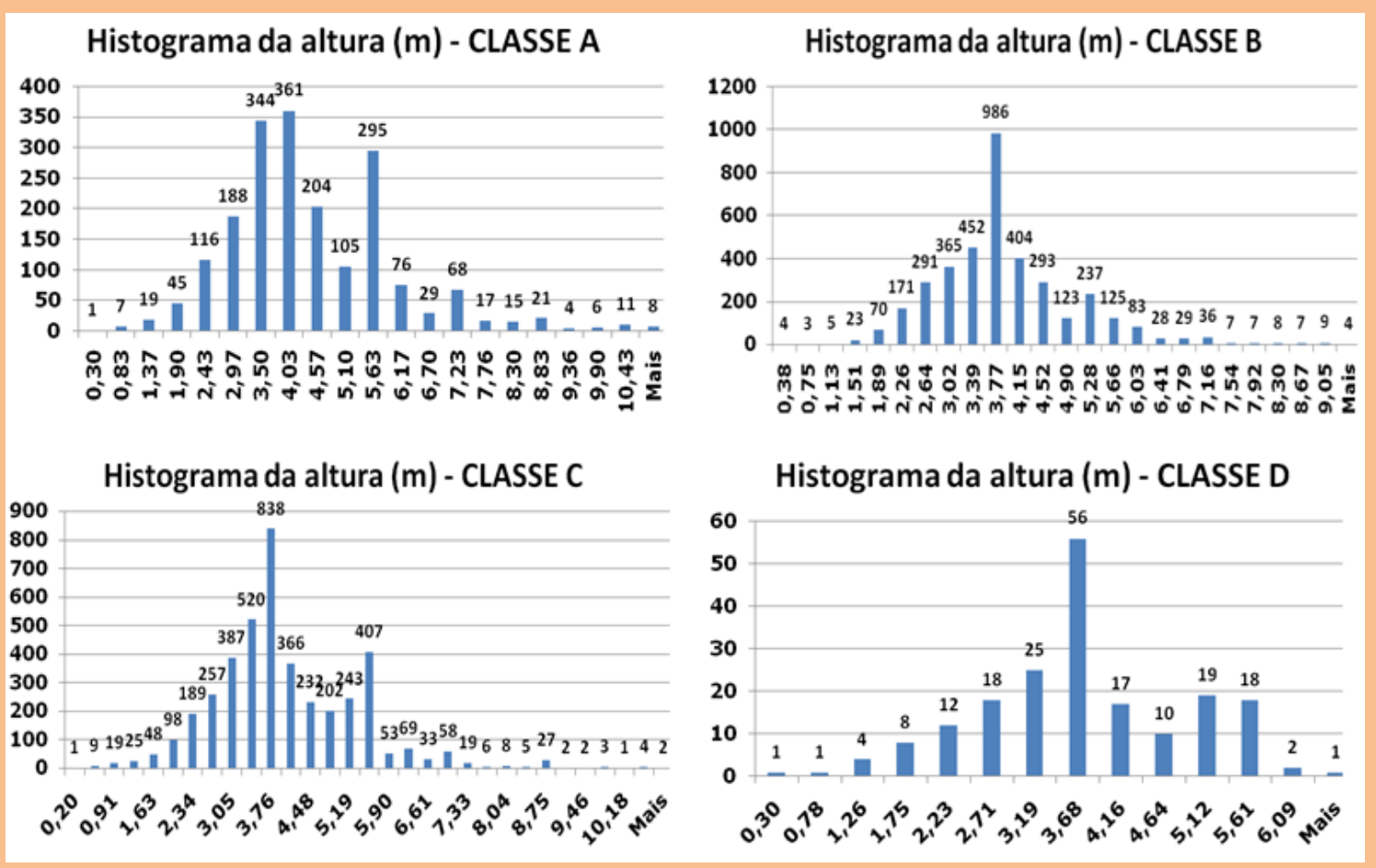

É hábito corriqueiro entre a população de Serra Talhada - PE a poda constante das árvores, são encontradas na cidade pouquíssimas árvores nas calçadas que conseguem atingir a plenitude de suas alturas, por isso não encontramos em nenhum dos quatro histogramas uma grande árvores de uma mesma rua. $\mathrm{O}$ resultado da comparação das alturas das árvores as classes sociais pode ser verificado na Figura 4.

Histograma da altura (m) - CLASSE D

quantidade de árvores altas, o que seria esperado se o hábito da poda não fosse tão arraigado na população.

Rushel e Leite (2002) realizaram o levantamento das árvores da cidade de Lajeado RS e amostraram 982 árvores e chegaram à CORRELAÇÃO ENTRE ÍNDICES DAS ÁRVORES E... 
conclusão que, aproximadamente, $36 \%$ dos indivíduos tinham altura inferior a 4 metros, o que implica dizer que $64 \%$ das árvores tinham altura superior a 4 metros. Em Serra Talhada PE o percentual de árvores menores que 4 metros é de $77 \%$ ou seja, $23 \%$ das árvores tem altura maior que 4 metros.

$\mathrm{Na}$ classe A percebe-se que o número de árvores com altura inferior a dois metros (árvores novas) é pequeno apenas 72 indivíduos (A soma das frequências das quatro primeiras classes do histograma), vale ressaltar que o plantio das árvores novas acompanha a mesma proporção de espécies apresentadas na Tabela 5, ou seja, a maioria das árvores são Ficus, Nin ou Cassia árvores que podem atingir naturalmente mais do que quatro metros de altura, o que significa que não está ocorrendo plantio acentuado de novas árvores. Esse resultado não era esperado, pois a classe A tem o seu único bairro ainda em crescimento, muitas casas novas estão sendo construídas, portanto, deveria haver um maior número de árvores pequenas. $\mathrm{O}$ número de árvores maiores que seis metros que, teoricamente, seriam as árvores mais antigas, também é relativamente pequeno.

A classe B tem o histograma mais próximo do que pode ser chamada de uma distribuição Normal de probabilidade, as alturas maiores e menores se dividem quase que equitativamente em torno da média, esse comportamento era esperado para essa classe, pois ela se insere em três bairros, onde dois deles são centrais (São Cristóvão e Nossa Senhora da Penha, ver Figura 3.), não permitindo, portanto, a construção de muitas casas, na maioria das vezes as novas árvores são plantadas na frente das casas novas. A construção de maior número de casas somente ocorre no bairro de São Cristóvão que faz fronteira com a Caatinga, permitindo ainda alguma expansão. Como a maioria das casas dessa classe social foram construídas há mais tempo a maioria das árvores já atingiram a altura desejada pelos moradores. O número de árvores novas (menores que 2 metros) é igual a 105 (Soma das cinco primeiras classes do histograma da classe B na Figura 4) é pequeno, e também é pequeno o número de árvores que ultrapassaram a altura maior que seis metros que é igual a 135 (soma das últimas nove classes do histograma da classe B. Figura 4).

$\mathrm{Na}$ classe $\mathrm{C}$, a altura das árvores se assemelha muito ao comportamento encontrado na classe A. Esses dois bairros (Bom Jesus e Caxixola, ver Figura 3.) em franca expansão territorial possuem muitos terrenos vagos prontos para receber construções. Interessante verificar como os histogramas das alturas da classe $\mathrm{C}$ e da classe A são parecidos, possuem apenas pequenas variações, portanto a análise feita para a classe A é semelhante à análise da classe $\mathrm{C}$.

$\mathrm{Na}$ classe $\mathrm{D}$, o comportamento quanto à distribuição das alturas é semelhante aos das classes $\mathrm{A}$ e $\mathrm{C}$, apenas o pequeno número de árvore usados na construção do histograma provoca uma pequena diferenciação na forma final, então é possível visualizar que existem poucas árvores novas (menores que 2 metros) e poucas árvores grandes (maiores que 6 metros).

A Tabela 3 apresenta o resultado da análise de variância para as alturas e a diferença significativa pelo teste de Tukey.

Tabela 3. Comparação das médias das alturas (m) pelo teste de Tukey. Na comparação letras iguais significam alturas estatisticamente iguais. $*$ = significativo ao nível de $5 \%$, ** = significativo ao nível de $1 \%$. 


\begin{tabular}{ccc}
\hline Classe social & Média & Comparação \\
\hline A & 4,20 & $\mathrm{a}^{* *}$ \\
C & 3,83 & $\mathrm{~b}^{* *}$ \\
B & 3,74 & $\mathrm{c}^{* *}$ \\
D & 3,42 & $\mathrm{~d}^{* *}$ \\
\hline
\end{tabular}

As árvores mais altas encontram-se na classe A e as mais baixas na classe $\mathrm{D}$, desta forma, existe diferença altamente significativa entre as médias

\section{c) Área de cobertura}

Uma das mais importantes funções das árvores urbanas é fornecer área de cobertura, gerando sombra e diminuindo assim a temperatura das alturas, conforme a classe social. A classe C possui as alturas maiores do que a classe B. ambiente, a Figura 5 apresenta os histogramas das áreas de cobertura para as quatro classes sociais.

Figura 5. Histogramas das áreas de cobertura das árvores das classes A, B, C e D

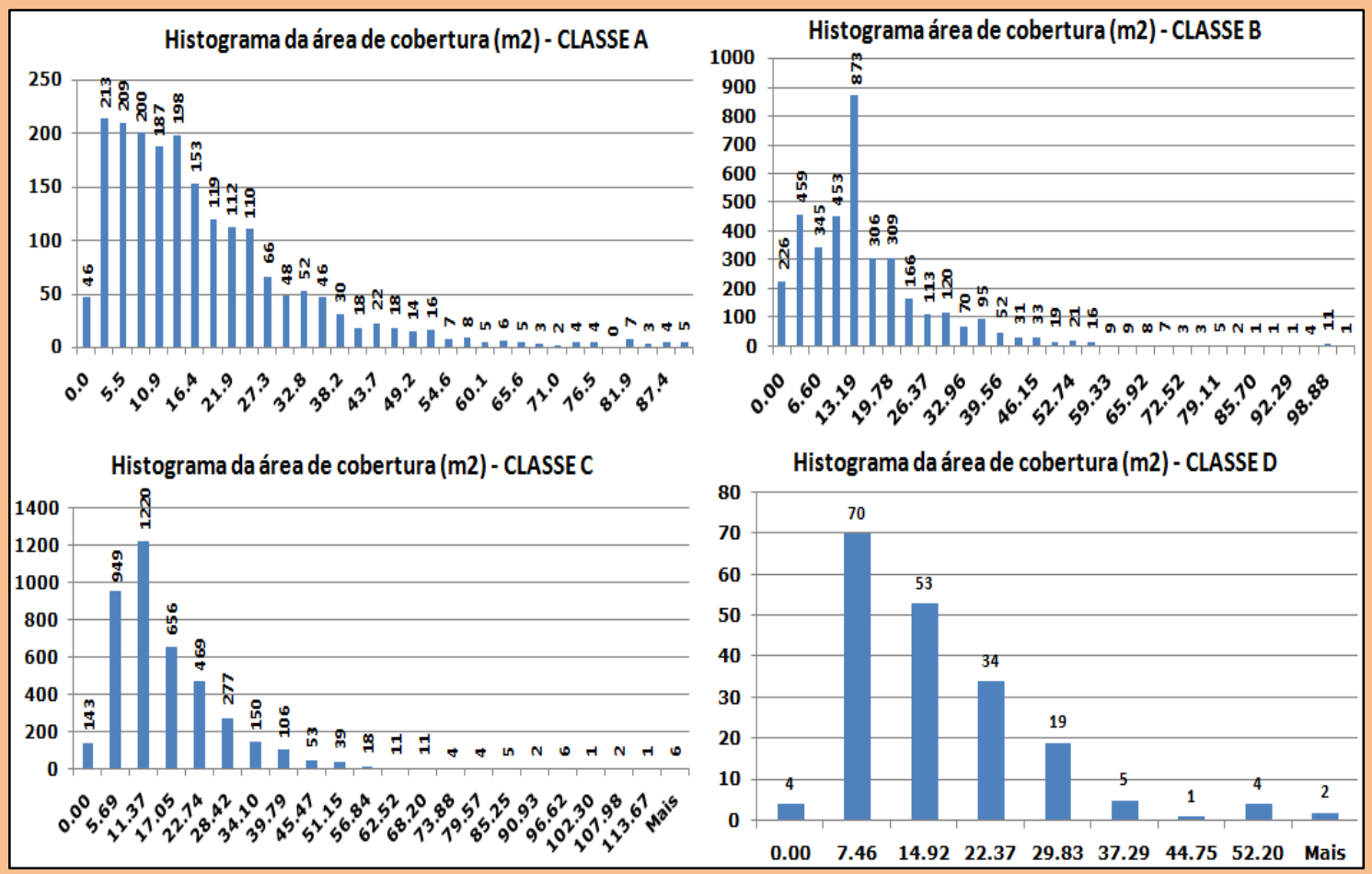

Em todas as classes nota-se um padrão, o número de árvores decresce à medida que as copas vão ficando maiores, esse fato extrapola a lógica esperada, que seria a de uma distribuição

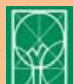

normal com histogramas semelhantes aos histogramas das alturas (Figura 3), pois existe uma forte correlação positiva entre a altura da árvore e sua área de cobertura. Esse fato se deve CORRELAÇÃO ENTRE ÍNDICES DAS ÁRVORES E... 
ao hábito da população de podar a copa com forma circular sistematicamente, não importando a altura da árvore.

Sendo Serra Talhada - PE uma cidade extremamente quente, com média anual de temperatura do ar de $32^{\circ} \mathrm{C}$, as árvores deveriam apresentar, na sua maioria, copas grandes, ainda mais que em torno de $68 \%$ das árvores existentes na cidade são Ficus spp, árvores que em estado natural possuem copas grandes. Esse fato é explicado pelo hábito de podar indiscriminadamente as árvores, dando preferência a árvores com copas definidas artificialmente.

A título de comparação é importante citar a pesquisa de Neto et al. (2007) que entre outros índices mediram as áreas das copas das árvores do centro da cidade de Aracajú - SE e o menor valor encontrado para área de cobertura por árvore foi de $66,75 \mathrm{~m}^{2}$ e o maior foi $156,63 \mathrm{~m}^{2}$, enquanto em Serra Talhada - PE de um total de aproximadamente 8000 árvores existem apenas 11 árvores com área superior a $100 \mathrm{~m}^{2}$, mais de $90 \%$ das árvores tem área inferior a $30 \mathrm{~m}^{2}$. Tal fato demonstra o atual estado de sombreamento em que se encontra a cidade de Serra Talhada $\mathrm{PE}$, as árvores, definitivamente, não cumprem um de seus importantes objetivos que é fornecer sombra.

Tabela 4. Comparação entre as médias da área de cobertura das classes sociais. * = significativo ao nível de $5 \%$, ** = significativo ao nível de $1 \%$.

\begin{tabular}{ccl}
\hline Classe social & Médias $\left(\mathrm{m}^{2}\right)$ & Comparação \\
\hline A & 16,34 & $\mathrm{a}^{* *}$ \\
B & 14,21 & $\mathrm{~b}$ \\
C & 13,86 & $\mathrm{~b}$ \\
D & 12,90 & $\mathrm{~b}$ \\
\hline
\end{tabular}

As médias acompanham diretamente as classes sociais como pode ser visualizado na Tabela 4, ou seja, as classes sociais mais abastadas possuem maiores áreas de cobertura.

A classe A possui a maior média para a área de cobertura entre as quatro classes. Para as outras

\section{d) Diversidade de espécies}

$\mathrm{Na}$ arborização urbana é importante que haja diversidade de espécies, pois assim é possível diminuir o ataque de pragas e doenças, fornecer mais opções de moradia e alimentação para espécies animais que utilizam as árvores, além de aproximar o ambiente urbano dentro do três classes sociais $\mathrm{B}, \mathrm{C}$ e $\mathrm{D}$ não é possível afirmar que exista diferença estatística entre elas. Porém mesmo sem existir diferença estatisticamente significativa vale ressaltar que a correlação entre as classes sociais e a área de cobertura é positiva $(\mathrm{A}>\mathrm{B}>\mathrm{C}>\mathrm{D})$.

possível ao ambiente encontrado na natureza, onde existe ampla diversidade. Os benefícios da diversidade são citados em diversos trabalhos como fator importante para a arborização urbana (MOTTER e MÜLLER, 2012; MELO e PIACENTINI, 2011; VIEIRA et al. 2012). 
Tabela 5. Quantidade de indivíduos das espécies arbóreas encontrados nas classes sociais de Serra

Talhada - PE em 2011/2012.

\begin{tabular}{|c|c|c|c|c|c|}
\hline \multirow[t]{2}{*}{ Nome comum } & \multirow[t]{2}{*}{ Nome científico } & \multicolumn{4}{|c|}{$\begin{array}{l}\text { Quantidade por classe } \\
\text { social }\end{array}$} \\
\hline & & $\mathrm{A}$ & $\mathrm{B}$ & $\mathrm{C}$ & $\mathrm{D}$ \\
\hline Abacateiro & Persea américa Mill & 0 & 2 & 2 & 0 \\
\hline Acácia & Acacia farnesiana L. & 136 & 305 & 373 & 4 \\
\hline Açafrão & Berberis aristata DC & 0 & 0 & 1 & 0 \\
\hline Albizia & Albizia julibrissin Durazzini & 6 & 10 & 10 & 0 \\
\hline Algaroba & Prosopis juliflora (Sw) DC & 7 & 46 & 48 & 2 \\
\hline Algodão da praia & Hibiscus pernambucensis Arruda & 9 & 9 & 5 & 0 \\
\hline Aroeira & Schinus terebinthifolia Raddi & 0 & 1 & 0 & 0 \\
\hline Azeitona & Syzygium cumini Lamark & 0 & 2 & 1 & 1 \\
\hline Brasileirinho & Erythrina indica picta. (L) B \& M & 30 & 44 & 115 & 6 \\
\hline Cajarana & Spondias macrocarpa Engl & 0 & 0 & 0 & 1 \\
\hline Cajueiro & Anacardium occidentale Linn & 0 & 1 & 0 & 0 \\
\hline Casuarina & Casuarina equisetifolia $\mathrm{L}$ & 1 & 0 & 0 & 0 \\
\hline Castanhola & Terminalia catappa $\mathrm{L}$ & 6 & 68 & 44 & 1 \\
\hline Catingueira & Caesalpinea pyramidalis Tul & 1 & 0 & 0 & 0 \\
\hline Chicha & Sterculia chicha St. Hill & 0 & 0 & 1 & 0 \\
\hline Cola & Cola acuminata P. Beauv & 12 & 4 & 21 & 0 \\
\hline Coqueiro & Cocos nucifera $\mathrm{L}$ & 3 & 1 & 0 & 0 \\
\hline Craibeira & $\begin{array}{l}\text { Tabebuia aurea (Manso) Benth \& Hook. f. ex. S. } \\
\text { Moore }\end{array}$ & 8 & 3 & 1 & 0 \\
\hline Esponja & Calliandra brevipes Benth & 0 & 1 & 1 & 0 \\
\hline Eucalipto & $\begin{array}{l}\text { Corymbia citriodora (Hook.) K.D.Hill \& } \\
\text { L.A.S.Johnson }\end{array}$ & 2 & 1 & 0 & 0 \\
\hline Ficus Benjamim & Ficus benjamina L & 1267 & 2598 & 2857 & 137 \\
\hline Flamboyam & Delonix regia Rafin & 8 & 9 & 8 & 0 \\
\hline Genipapo & Genipa americana L & 0 & 1 & 0 & 0 \\
\hline Goiabeira & Psidium guajava $\mathrm{L}$ & 1 & 7 & 6 & 0 \\
\hline Leucena & Leucaena leucocephala (Lam) de Wit & 1 & 0 & 0 & 0 \\
\hline Mamoeiro & Carica papaya $\mathrm{L}$ & 2 & 5 & 5 & 0 \\
\hline Mangueira & Mangifera indica L & 2 & 6 & 9 & 0 \\
\hline Mororó & Bauhinia variegata $\mathrm{L}$ & 16 & 0 & 1 & 0 \\
\hline Nim indiano & Azadirachta indica A. Juss & 325 & 547 & 544 & 38 \\
\hline Oitizeiro & Licania tomentosa Benth & 5 & 8 & 0 & 0 \\
\hline Olho-de- pombo & Adenanthera pavonina $\mathrm{L}$ & 5 & 16 & 15 & 0 \\
\hline
\end{tabular}




\begin{tabular}{llcccc} 
Pachira & Pachira aquática Aublet & 6 & 4 & 11 & 0 \\
Palmeira & Roystonea oleracea Jacq & 2 & 10 & 3 & 0 \\
imperial & Caesalpinia echinata Lam & 12 & 14 & 10 & 0 \\
Pau-Brasil & Aspidosperma pyrifolium Mart & 0 & 1 & 0 & 0 \\
Pereiro & Duranta erecta aurea Linn & 17 & 3 & 1 & 0 \\
Pingo de ouro & Pinus elliottii Engelm & 1 & 1 & 0 & 0 \\
Pinus & Mimosa caesalpiniaefolia Benth & 4 & 2 & 2 & 0 \\
Sabiá & Manilkara achras Mill & 1 & 0 & 0 & 0 \\
Sapotizeiro & Spondia purpurea L & 0 & 4 & 4 & 0 \\
Sirigüela & Clitoria fairchidiana Howard & 5 & 3 & 1 & 0 \\
Sombreiro & Tamarindus indica L & 5 & 12 & 1 & 0 \\
Tamarindo & Spondias tuberosa Arr. Cam & 1 & 1 & 1 & 1 \\
Umbuzeiro & & & & & \\
\hline
\end{tabular}

Como pode ser visto na Tabela 5 o número espécies encontradas para a classe A (33), classe B (37) e classe C (31) é próximo, porém para a classe $\mathrm{D}$ o número é bem menor, apenas nove espécies. A existência de mais de 30 espécies para as classes A, B e C na verdade mascara a verdadeira situação da biodiversidade encontrada nos bairros em que as classes estão inseridas. As quatro classes sociais duas espécies dominantes, o Ficus benjamina (69\%) e o Nim indiano (15\%) (Azadirachta indica), em cada classe social o percentual de indivíduos juntos dessas duas espécies representam mais de $82 \%$ das árvores.

Tabela 6. Índices de Shannon para as classes sociais

\begin{tabular}{cc}
\hline Classe social & Índice de Shannon \\
\hline A & 1,28 \\
B & 1,16 \\
C & 1,13 \\
D & 0,91 \\
\hline
\end{tabular}

Como pode ser verificado na Tabela 6 , o índice de Shannon foi diretamente proporcional as classes sociais, ou seja, as classes sociais de maior poder aquisitivo também possuem maior diversidade de espécies arbóreas em suas calçadas.

Raber e Rebelato (2010) analisando qualitativamente e quantitativamente a arborização viária da cidade de Colorado - RS encontraram um índice de Shannon de 2,95, mais de duas vezes superior ao encontrado em Serra Talhada - PE, os pesquisadores chegaram à conclusão de que a cidade de Colorado é mediamente bem arborizada e que a diversidade arbórea é razoável, tendo $51 \%$ de suas espécies nativas. 


\section{e) Estatísticas descritivas}

A comparação das medidas de tendência central (média aritmética, mediana e moda) e as medidas de dispersão (variância e desvio padrão), além do máximo e do mínimo dos índices, altura e área de cobertura das árvores estão apresentadas na Tabela 7.

Tabela 7. Estatísticas clássicas para a altura e cobertura das árvores de Serra Talhada - PE (2011 - 2012). Med $=$ mediana, Var = variância, Des $=$ desvio padrão, Máx = máximo e Min = mínimo

\begin{tabular}{ccccccccc}
\hline Classe social & Índices & \multicolumn{7}{c}{ Estatísticas } \\
\cline { 3 - 9 } A & Média & Moda & Med & Var & Des & Máx & Mín \\
& Altura $(\mathrm{m})$ & 4,20 & 3,84 & 3,77 & 2,84 & 1,69 & 23,76 & 0,30 \\
B & Cobertura $\left(\mathrm{m}^{2}\right)$ & 16,34 & 12,60 & 16,34 & 230,61 & 15,19 & 120,18 & 0,00 \\
& Altura & 3,74 & 3,70 & 3,58 & 1,47 & 1,21 & 23,00 & 0,30 \\
& Cobertura $\left(\mathrm{m}^{2}\right)$ & 14,21 & 10,46 & 11,54 & 202,44 & 14,23 & 201,06 & 0,00 \\
& Altura & 3,83 & 3,63 & 3,76 & 1,79 & 1,34 & 23,00 & 0,30 \\
\multirow{2}{*}{ D } & Cobertura $\left(\mathrm{m}^{2}\right)$ & 13,86 & 10,46 & 8,12 & 219,47 & 14,81 & 363,73 & 0,00 \\
& Altura & 3,42 & 3,28 & 3,68 & 1,35 & 1,16 & 6,57 & 0,30 \\
& Cobertura $\left(\mathrm{m}^{2}\right)$ & 12,90 & 10,21 & 7,46 & 158,51 & 12,59 & 96,94 & 0,00 \\
\hline
\end{tabular}

Na média aritmética para a altura é possível perceber um indicativo de correlação diretamente proporcional com o poder econômico de cada classe social. A classe A tem maior valor que as classes $\mathrm{B}, \mathrm{C}$ e $\mathrm{D}$. A média da altura da classe $\mathrm{C}$ é maior que a da classe B e ambas são maiores que a D.

A mediana forneceu para a altura valores diretamente proporcionais a classe social, sem haver inversão em nenhuma das classes.

Pelas modas (valor da altura que possui maior coluna) apresentadas nos histogramas para as quatro classes percebe-se claramente que a moda das alturas acompanha diretamente as classes sociais, as maiores modas são as das classes mais abastadas.

Quando o atributo de comparação é a área de cobertura a correlação diretamente proporcional fica bem clara, pois todos os três índices utilizados (média, mediana e moda) forneceram valores em ordem decrescente da classe A para a classe D, com a observação de que as medianas das classes $\mathrm{B}$ e $\mathrm{C}$ foram exatamente iguais.

Os desvios padrões forneceram valores maiores para a classe A para os dois atributos altura e área de cobertura e menores para a classe $\mathrm{D}$, também para os dois atributos, fornecendo ainda maiores valores para a classe $\mathrm{C}$ do que para a classe B em ambos.

Para os valores máximos não houve nenhum indicativo de correlação e para os valores mínimos não foi possível a verificação, porque as árvores somente eram medidas se tivessem o mínimo de 0,30 metros. As áreas de coberturas mínimas de 0,00 metros quadrados representam as árvores que sofreram podas drásticas em que todas as folhas e pequenos galhos foram retirados, restando apenas os galhos mais grossos e não possuíam no momento da coleta dos dados nenhuma cobertura.

CORRELAÇÃO ENTRE ÍNDICES DAS ÁRVORES E... 
Talvez os indicadores da arborização possam ser utilizados na cidade de Serra Talhada - PE para efetuar a divisão geográfica entre as classes sociais dentro da área urbana, porém mais pesquisas deve ser realizadas para comprovação ou não dessa hipótese.

\section{CONCLUSÕES}

1) Existe correlação diretamente proporcional entre as classes sociais e os índices: a altura, a área de cobertura, densidade por metro quadrado e índice de diversidade de Shannon das árvores na cidade de Serra Talhada - PE.

A hipótese inicial de que as classes sociais mais abastadas possuíam árvores em maior quantidade e maiores em altura e cobertura do que as classes menos favorecidas foi confirmada, acreditamos que isso se deve a dois fatores principais, maior conscientização ecológica e a existência de maiores áreas disponíveis nos terrenos das casas para plantio.

2) A cobertura vegetal nas calçadas de Serra Talhada - PE é deficiente. O hábito da poda prejudica de maneira intensa a área de cobertura da cidade, a predominância de apenas duas espécies o Nin e o Ficus representando $83 \%$ das árvores da cidade e sendo elas resistentes as podas constantes, ajuda a manter a cidade ensolarada, existe claramente uma escolha mais forte pela estética do que pelo conforto.

\section{REFERÊNCIAS BIBLIOGRAFICAS}

BEZERRA, J.A.; LIMA, K.Q. de. Desigualdades socioespaciais em pequenas cidades: a segregação residencial na cidade de Pau dos Ferros-RN. GEOTemas, Pau dos Ferros, Rio Grande do Norte, Brasil. v. 1, n. 1, p. 43-54, jan./jun. 2011.

DANTAS, I.C.; SOUZA, C. M. C. de. Arborização urbana na cidade de Campina Grande - PB: inventário e suas espécies. Rev. de Biologia e Ciências da Terra. Vol. 4, n. 2, 2004.

LEAL, L.; BIONDI, D.; ROCHADELLI, R. Custos de implantação e manutenção da arborização de ruas da cidade de Curitiba, PR. R. Árvore, Viçosa-MG, v.32, n.3, p.557-565, 2008.

LIMA FILHO, C.T. de. Denominação de bairros de Serra Talhada. Disponível em: http://www.serratalhada.net/cidade/mostra.asp?noticia=noticia63.asp. Acesso em: 31/01/2012.

IBGE - Instituto Brasileiro de Geografia e Estatística. Censo Demográfico de 2010. Disponível em: http://censo2010.ibge.gov.br/images/pdf/censo2010/questionarios/questionario_amostra_cd2010.pdf. (a). Acesso em: 13/03/2012. 
IBGE - Instituto Brasileiro de Geografia e Estatística. Censo Demográfico de 2010. Disponível em: http://www.ibge.gov.br/home/estatistica/populacao/censo2010/tabelas_pdf/total_populacao_pernambuco. pdf. (b). Acesso em: 13/03/2012.

LUCHIARI, A. Identificação da cobertura vegetal em áreas urbanas por meio de produtos de sensoriamento remoto e de um sistema de informação geográfica. Rev. do Departamento de Geografia. v. 14, p. 47-59. 2001.

MELO, A.S., O que ganhamos 'confundindo' riqueza de espécies e equabilidade em um índice de diversidade? Biota Neotrop, vol. 8, no. 3, pg. 21-28, Jul./Set. 2008.

MELO, E.F.R.Q.; PIACENTINI, C.A.M. Diversidade da arborização Urbana no Município de Colorado (RS). Ambiência, v. 7, N. 2, p. 339-352, 2011.

MENEGHETTI, G.I.P. Estudo de dois métodos de amostragem para inventário da arborização de ruas dos bairros da orla marítima do município de Santos, SP. 2003. Dissertação (Mestrado em Recursos Florestais) - Escola Superior de Agricultura "Luiz de Queiroz", Universidade de São Paulo. 2003.

M.M.E. MINISTÉRIO DAS MINAS E ENERGIA. Diagnóstico do município de Serra Talhada.

Projeto cadastro de fontes de abastecimento por água subterrânea. 2005. Disponível em:

http://www.cprm.gov.br/rehi/atlas/pernambuco/relatorios/SETA148.pdf. Acesso em 09/11/2013.

MODELSKi, G. World Cities: -3000 to 2000. Em national geographic brasil, edição n. 141, dezembro de 2011 , p. 52-53.

MOTTER, N.; MÜLLER, N.G. Diagnóstico da arborização urbana no município de Tuparendi - RS. REVSBAU, Piracicaba - SP, v.7, n.4, p. 27-36, 2012.

NETO, E.M.L.; RESENDE, W.X.; SOUZA, R. Melo e. Áreas Verdes Públicas do Centro de Aracaju-SE: Análise Fitogeográfica. Revista da Fapese, v.3, n. 2, p. 5-16, jul./dez. 2007.

PINTO, E. de P.P. AMOROZO, M.C. de M.; FURLAN, A. Conhecimento popular sobre plantas medicinais em comunidades rurais de mata atlântica - Itacaré, BA, Brasil. Rev. Acta botanica brasilica. v. 20, n. 4, p. 751-762. 2006.

RABER, A.P.; REBELATO, G.S. Arborização viária do município de Colorado, RS - Brasil: análise quali-quantitativa. Revista Brasileira de Arborização Urbana, Piracicaba - SP, v.5, n.1, p.183-199, 2010 .

ROSSATTO, D.R.; TSUBOY, M.S.F.; FREI, F. Arborização urbana na cidade de Assis - SP: uma abordagem quantitativa. Revista Brasileira de Arborização Urbana, Piracicaba, v.3, n.3, set. p. 1-16. 2008. 
RUSCHEL, D.; LEITE, S.L. de C. Arborização urbana em uma área da cidade de Lajeado, Rio Grande do Sul, Brasil. Caderno de Pesquisa Sér. Bio. Santa. Cruz do Sul, v. 14, n. 1, p. 7-24, jan./jun. 2002.

SILVA, A.G.A arborização urbana em cidades de pequeno porte: avaliação quantitativa e qualitativa. 2000. 150 f. Dissertação (Mestrado em Ciências Florestais), Universidade Federal de Viçosa - Viçosa, 2000.

SILVA, G.J.A. da.; WERLE, H.J.S. Planejamento urbano e ambiental nas municipalidades: da cidade à sustentabilidade, da lei à realidade. Revista eletrônica da área Paisagem e Ambiente, FAU. USP n. 05, dezembro 2007. Disponível em: http://www.usp.br/fau/depprojeto/gdpa/paisagens/artigos/2007SilvaWerle-planejamentoUrbanoSustentabilidade.pdf Acesso em: 18/03/2013.

SILVA, G. F. da; CURTO, R. De A.; SOARES, C. P. B. e PIASSI, L. de C.. Avaliação de métodos de medição de altura em florestas naturais. Rev. Árvore . 2012, vol.36, n.2, pp. 341-348. Disponível em: http://www.scielo.br/scielo.php?pid=S0100-67622012000200015\&script=sci_arttext. Acesso em: $09 / 11 / 2013$.

VIDAL, M.; GONÇALVES, W. Curso de paisagismo. Viçosa, MG: UFV, 1999. P. 76.

VIEIRA, F. A. B.; CALDEIRA, D. R. M.; BATISTA, J. A. e MOREIRA, J. P. P. C. O geoprocessamento como ferramenta para a avaliação quantitativa e qualitativa da arborização urbana do município de Colorado do Oeste - RO. In: III Congresso Brasileiro de Gestão Ambiental, 2012, Goiânia-GO. Anais do III Congresso Brasileiro de Gestão Ambiental. Goiânia: IBEAS - Instituto Brasileiro de Estudos Ambientais, 2012, p. 1-10.

VILAÇA, F. Espaço intra-urbano no Brasil. Studio Nobel - FAPESP; Lincoln Institute. São Paulo Brasil. p 363. 2001.

WESTPHAL, M.F.O Movimento Cidades/Municípios Saudáveis: um compromisso com a qualidade de vida. Ciência e Saúde Coletiva, v.5, n.1, p. 39-51, 2000. 